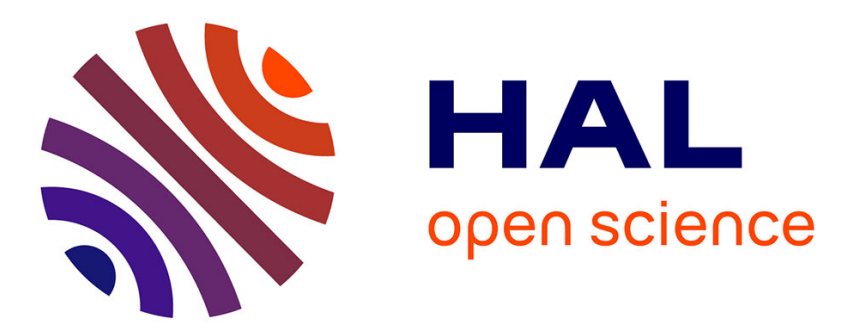

\title{
NONLINEAR ELASTICITY EFFECTS IN THE DYNAMIC FRACTURE OF POLYMERS
}

\author{
M. Wheel, P. Leevers
}

\section{To cite this version:}

M. Wheel, P. Leevers. NONLINEAR ELASTICITY EFFECTS IN THE DYNAMIC FRACTURE OF POLYMERS. Journal de Physique IV Proceedings, 1991, 01 (C3), pp.C3-549-C3-556. 10.1051/jp4:1991377 . jpa-00250522

\section{HAL Id: jpa-00250522 https://hal.science/jpa-00250522}

Submitted on 1 Jan 1991

HAL is a multi-disciplinary open access archive for the deposit and dissemination of scientific research documents, whether they are published or not. The documents may come from teaching and research institutions in France or abroad, or from public or private research centers.
L'archive ouverte pluridisciplinaire HAL, est destinée au dépôt et à la diffusion de documents scientifiques de niveau recherche, publiés ou non, émanant des établissements d'enseignement et de recherche français ou étrangers, des laboratoires publics ou privés. 


\title{
NONLINEAR ELASTICITY EFFECTS IN THE DYNAMIC FRACTURE OF POLYMERS
}

\author{
M.A. WHEEL and P.S. LEEVERS \\ Imperial College of Science. Technology and Medicine, \\ Department of Mechanical Engineering. Exhibition Road, \\ GB-London SW7 2BX, Great-Britain
}

\begin{abstract}
Résumé : Un modèle élastique non linéaire de l'essai de rupture en double torsion à grande vitesse (HSDT), utilisé pour tester des tuyaux de polyethylène, donne une dispersion des valeurs de la résistance à la rupture dynamique. Une technique permettant de déterminer le module de cisaillement approprié au HSDT a été développée. Les données obtenues montre que les modules de cisaillement chutent lorsque le cisaillement crôit. le modèle numérique a été modifié pour inclure ce comportement élastique non linéaire. les valeurs de résistance ainsi recalculées sont beaucoup moins dispersées.
\end{abstract}

ABSTRACT:- A linear elastic model of the High Speed Double Torsion fracture test, which is used to test pipe grade polyethylenes, produces scattered dynamic fracture resistance values. A technique that determines shear modulus data appropriate to the HSDT has developed. The data obtained from this technique indicate that the shear moduli fall as the applied shear strain is increased. The numerical model has been modified to include this nonlinear elastic behaviour. The recomputed resistance data shows significantly less scatter.

\section{INTRODUCTION}

Polyethylene (PE) piping is now being used extensively for gas distribution. Rapid Crack Propagation (RCP), with crack speeds of up to $350 \mathrm{~m} / \mathrm{s}$, is a possible but unlikely failure mode. The gas utilities and pipe producers perform full scale RCP tests on pipes to establish safe operating conditions [1]. However, the material manufacturers would like to identify prospective pipeline materials, characterised by a high dynamic fracture toughness, $G_{D}$, prior to extrusion and full scale testing. To meet this requirement the High Speed Double Torsion Test has been developed to produce controlled RCP in laboratory scale samples [2, 3]. Loading conditions and crack velocity, å, are monitored. A post-mortem analysis is used to determine $G_{D}$. The shear modulus of the material is required to perform this analysis. Initially linear elastic material behaviour was assumed and ultrasonic methods were used to determine modulus values. The resulting $G_{D}$ data was somewhat scattered, so a technique to determine shear modulus data at strains and strain rates appropriate to the fracture test has been developed.

\section{THE HIGH SPEED DOUBLE TORSION TEST}

The test sample consists of a $6 \mathrm{~mm}$ thick plate measuring $100 \times 200 \mathrm{~mm}$ (Fig.1). A $1 \mathrm{~mm}$ deep ' $\mathrm{V}$ ' groove is machined on the underside of the sample along the major axis. A prenotch is machined part way along the 
axis and a $1.5 \mathrm{~mm}$ deep razor blade slit is also scored along this line on the upper surface of the specimen. The sample is supported at four points and impacted normally close to the notched end causing the two halves to deform as rectangular sectioned torsion beams rotating in opposite senses. The resulting torsional disturbance travels along each half of the specimen and loads the notch tip, causing a crack to initiate some time after impact and then propagate axially, at speeds of up to $240 \mathrm{~m} / \mathrm{s}$. The load history is measured by piezo-electric load cells under the load plane supports while the crack length is monitored in $10 \mathrm{~mm}$ increments during the test, using a pattern of conductive and resistive strips painted onto the lower surface of the sample. The striker velocity is found by measuring the time of flight between two infra-red detectors just prior to impact and is assumed to remain constant.

Both a high density and a medium density grade PE have been tested using the HSDT technique. The majority of tests were performed at $0^{\circ} \mathrm{C}$, for two reasons:-

i) This is the likely minimum operating temperature of buried PE pipes.

ii) The limited number of tests performed at $23^{\circ} \mathrm{C}$ all exhibited permanent deformation invalidating any elastic analysis.

Samples of each material were tested using striker speeds in the range of $14-31 \mathrm{~m} / \mathrm{s}$. Continuous constant velocity crack growth, at velocities in the range of $125-240 \mathrm{~m} / \mathrm{s}$, was observed A few tests were performed using striker speeds between $7-14 \mathrm{~m} / \mathrm{s}$. Under these conditions several arrest markings were frequently seen on the fracture surface.

Fig. 1 The High Speed Double Torsion Test

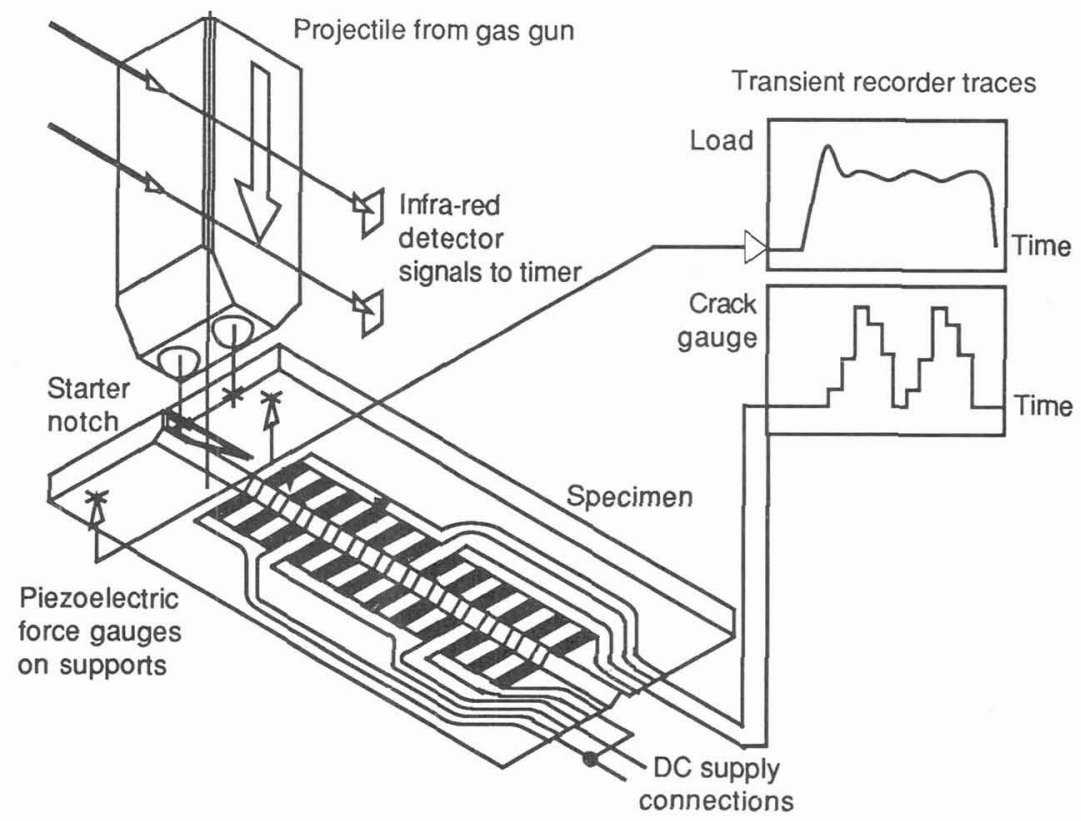

\section{THE ULTRASONIC METHOD OF MEASURING SHEAR MODULUS.}

A direct contact ultrasonic technique has been used to determine shear wave speeds in the materials that were fracture tested. Once the wave speed is known a shear modulus, which corresponds to the low strain, high strain rate ultrasonic loading, can be found. A $25 \mathrm{~mm}$ square, $1 \mathrm{~mm}$ thick wafer of each 
material was machined from fractured HSDT samples. An ultrasonic shear wave probe was mounted on each wafer in turn using a molasses couplant. The wafer and probe were placed in a refrigerator and cooled to $0^{\circ} \mathrm{C}$. The probe was then excited and the response recorded using a transient recording oscilloscope. Fig. 2 shows the response produced by the high density grade. The first and subsequent shear wave reflections are identified and the phase shift between successive reflections can be seen. Material attenuation reduces the amplitude of each succeeding reflection.

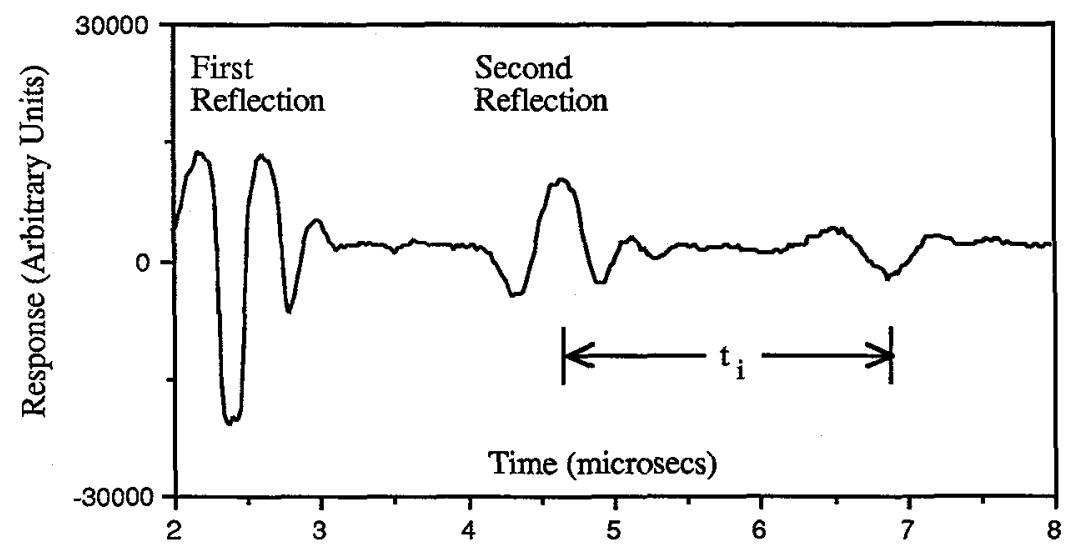

Fig.2 Ultrasonic Response Showing Shear Wave Reflections

Two methods are available to determine the shear wave speed, $\mathrm{C}_{\mathrm{S}}$. If the time interval between two consecutive reflections, $t_{i}$, is measured then $C_{S}$ is given by:-

$$
\mathrm{C}_{\mathrm{s}}=\frac{2 \mathrm{~T}}{\mathrm{t}_{\mathrm{i}}}
$$

where $\mathrm{T}$ is the wafer thickness. Alternatively, a Fourier transformation of two successive reflections can be obtained and the resonances of the wafer identified (Fig.3).

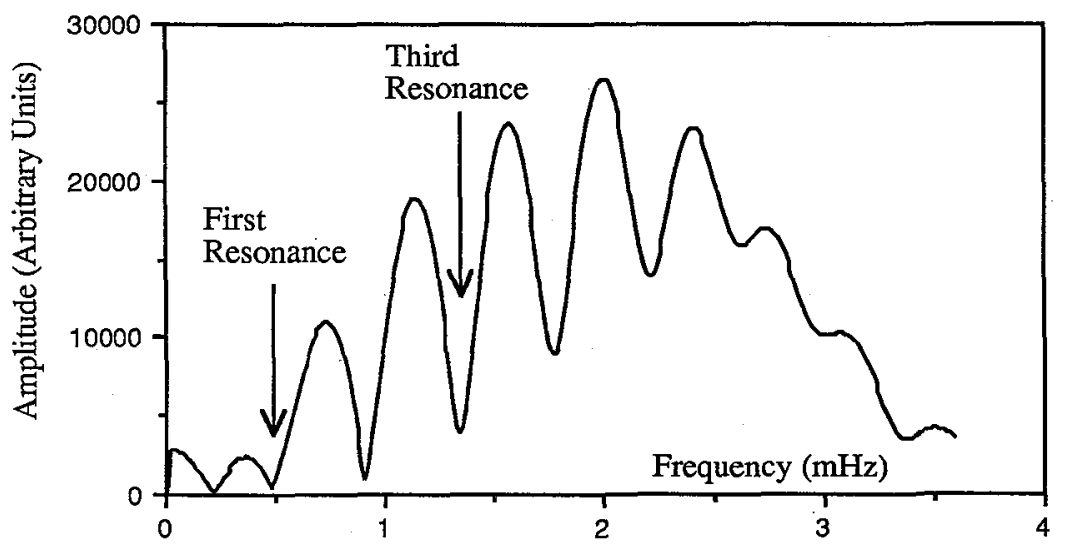

Fig.3 Fourier Transformation of Part of the Ultrasonic Response Depicted in Fig.2 
$\mathrm{C}_{\mathrm{S}}$ is then given by:-

$$
\mathrm{C}_{\mathrm{S}}=\frac{2 \mathrm{Tf}}{\mathrm{n}}
$$

where $f_{n}$ is the frequency of the $n$th resonance. $C_{S}$ is independent of frequency over the band of resonances that are excited by the probe. The shear modulus, $\mu_{0}$ is then:-

$$
\mu_{0}=\rho C_{S}^{2}
$$

where $\rho$ is the mass density. Data obtained for the two materials are given in Table 1 .

Table 1 Material Properties

\begin{tabular}{|c|c|c|}
\hline Material & $\begin{array}{c}\text { Ultrasonically } \\
\text { Measured Shear } \\
\text { Modulus, GPa }\end{array}$ & Density, $\mathrm{kG} / \mathrm{m}^{3}$ \\
\hline HDPE 2 & 1.08 & 960 \\
\hline MDPE 1 & 0.85 & 939 \\
\hline
\end{tabular}

\section{A LINEAR ELASTIC MODEL OF THE HSDT TEST.}

Each half of the sample can be modelled as a torsion beam, unrestrained behind the crack tip $(x<a)$ but restrained by an elastic foundation ahead of the crack tip ( $x>a)$, which exerts a restoring torque at any section that is proportional to its rotation, $\phi(x, t)$. Kanninen [4] developed a similar model of the double cantilever beam sample. The model for the HSDT test is:-

$$
\mu_{0} \mathrm{~K} \phi_{\mathrm{xx}}-\rho \mathrm{I} \phi_{\mathrm{tt}}-\mathrm{H}(\mathrm{x}-\mathrm{a}) \sigma \phi=0
$$

where $\mathrm{H}$ is the usual Heaviside step function. The torsional rigidity of the beam section is $\mu_{0} \mathrm{~K}$, the polar moment of inertia of the section per unit length is $\rho I$ and $\sigma$ is the torsional stiffness per unit length of the foundation. The torsional wave speed, $C_{T}\left\{=\left(\mu_{0} \mathrm{~K} / \rho \mathrm{I}\right)^{1 / 2}\right\}$, is typically $250 \mathrm{~m} / \mathrm{s}$ for a $6 \mathrm{~mm}$ thick sample.

The initial conditions acknowledge that the sample is undeformed and at rest prior to loading. Since the striker velocity is assumed to remain constant during the test, the design of the striker and support then ensures that the load plane rotation rate remains almost constant throughout, thus establishing the load plane boundary condition. Crack growth is simulated by allowing the foundation to translate at the crack tip speed after fracture initiation. Equation (4) can then be solved numerically by integrating along the characteristics [5], to determine the sample deformation as a function of time. High speed photography has been used to confirm that measured deformations agree with those predicted by the model represented by equation (4).

Invoking the conventional energy balànce argument $G_{D}$ can then be determined at each timestep in the integration procedure by calculating the imbalance between the rate at which external work is being 
supplied to the sample, $\mathrm{dU} \mathrm{W}_{\mathrm{W}} / \mathrm{dt}$, and the rates of increase of kinetic energy, $\mathrm{dU}_{\mathrm{K}} / \mathrm{dt}$, and strain energy, $\mathrm{dU}_{\mathrm{S}} / \mathrm{dt}$, within the specimen :-

$$
G_{D}=\frac{1}{B_{C}^{a}}\left\{\frac{d U_{W}}{d t}-\frac{d U_{S}}{d t}-\frac{d U_{K}}{d t}\right\}
$$

where $B_{C}$ is the width of the fracture surface. This approach avoids referring to local parameters. $G_{D}$ remains approximately constant for each test, but, as Fig.4 shows, when mean $G_{D}$ values from a series of tests performed on both materials are plotted as a function of crack velocity, considerable scatter is seen. This scatter is systematic: at a given crack velocity, a higher $G_{D}$ value is yielded by a test performed at a higher impact speed. Another inconsistent feature of the model is that the predicted applied load is much greater than that actually measured during a typical test, suggesting that inappropriate modulus values are being used in the simulations.

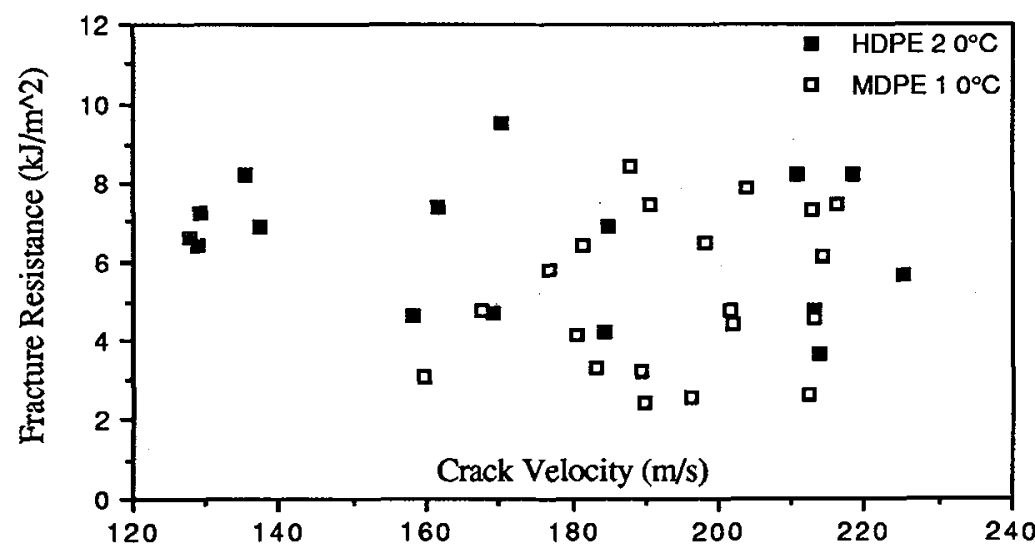

Fig.4 Variation in Fracture Resistance with Crack Velocity for Medium and High Density PE Grades (Linear Elastic Analysis)

\section{DETERMINATION OF SHEAR MODULUS VALUES APPROPRIATE TO THE HSDT TEST}

By imposing a high hydrostatic pressure and subjecting samples to shear strains of up to 5\% Truss [6] has shown that pipe grade PE materials exhibit nonlinear behaviour. In order to determine shear modulus values appropriate to the HSDT test a technique, which makes use of the HSDT geometry, has been developed. Two independent rectangular sectioned torsion beams are fastened together at one end, to produce a sample with the same dimensions as the fracture test piece These samples are then loaded by impact using a range of striker speeds in the HSDT test rig, with the striker twisting each beam at its unrestrained end. Fig. 5 shows the assumed deformation of the sample during the test. Since the region ahead of the disturbance is unstrained, the front of the disturbance propagates at a torsional wave speed determined by the ultrasonically measured low strain shear modulus, $\mu_{0}$. 




Fig.5 Assumed Deformation in the Modulus Test Piece

The torque applied to each beam, $T$, can be determined from the mean measured load, while the uniform twist induced in the disturbed region, $\phi_{x}$, is given by :-

$$
\phi_{\mathrm{x}}=\frac{\phi_{\mathrm{t}}(0, \mathrm{t})}{\mathrm{C}_{\mathrm{T}}}
$$

The twist can be varied simply by changing the impact speed. The effective shear stress, $\tau_{\mathrm{EFF}}$, and maximum shear strain, $\gamma_{\mathrm{MAX}}$, in any rectangular section are defined by :-

$$
\tau_{\mathrm{EFF}}=\mathrm{T} \frac{\mathrm{B}}{\mathrm{K}}, \quad \gamma_{\mathrm{MAX}}=\mathrm{B} \phi_{\mathrm{x}}
$$

where $B$ is the sample thickness. The shear strain induced in the disturbed region thus depends on the striker velocity. An 'effective' secant shear modulus, $\mu_{\mathrm{SEC}}$, can then be defined as :-

$$
\mu_{\text {SEC }}=\frac{\tau_{\text {EFF }}}{\gamma_{\text {MAX }}}=\frac{T}{K \phi_{x}}=\frac{T B}{K \gamma_{\text {MAX }}}
$$

This allows $\mu_{\mathrm{SEC}}$ to be found and plotted as a function of the shear strain. Fig. 6 shows how $\mu_{\mathrm{SEC}}$ varies with shear strain for the high density PE grade. The ultrasonically measured shear modulus value is also plotted at zero strain. Clearly the material is exhibiting nonlinear behaviour under impact loading conditions, the effective shear modulus falling as the applied shear strain is increased. A power law approximation:-

$$
\mu_{\mathrm{SEC}}=\frac{\mu_{0}}{\left(1+\mathrm{m} \gamma_{\mathrm{MAX}}\right)}
$$

leads to an 'effective' tangent shear modulus, $\mu_{\mathrm{TAN}}$, defined by $\mathrm{d} \tau_{\mathrm{EFF}} / \mathrm{d} \gamma_{\mathrm{MAX}}$ :-

$$
\mu_{\mathrm{TAN}}=\frac{\mu_{0}}{\left(1+\mathrm{m} \gamma_{\mathrm{MAX}}\right)^{2}}
$$

The decay constants, $\mathrm{m}$, for the high density and medium density materials were found to be 14 and 19 per 
unit shear strain respectively.

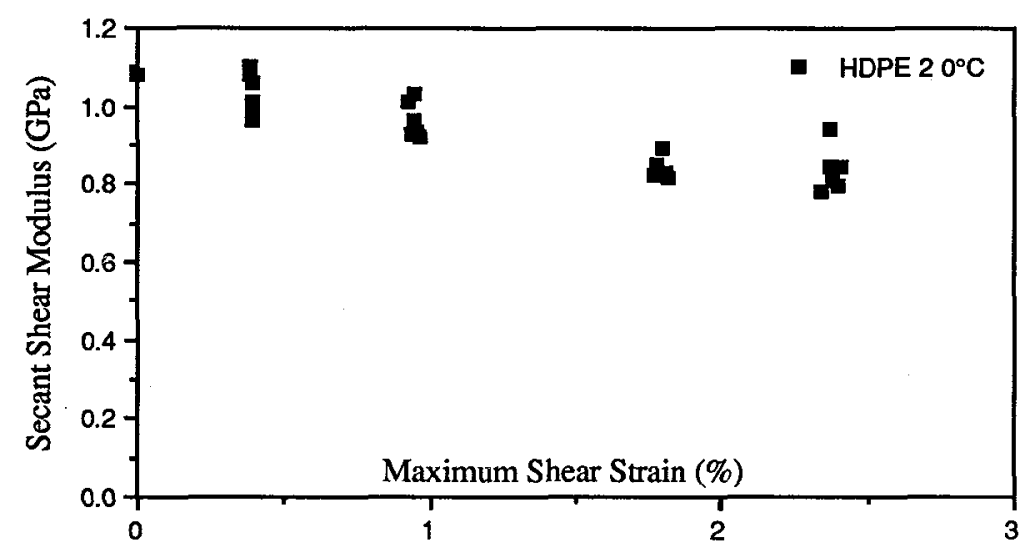

Fig.6 Variation in 'Effective' Secant Shear Modulus with Shear Strain for the High Density PE Grade

\section{A NON LINEAR ELASTIC MODEL OF THE HSDT TEST}

Two improvements can be introduced simultaneously into the existing model. Firstly the variation in 'effective' tangent shear modulus with strain given by equation (10) can be included. The second enhancement is to consider the suppression of free warping of the rectangular beam sections, coupled with the appearance of axial stresses, in the region where the twist varies [7]. The model is now described by the nonlinear equation:-

$$
2(1+v) \mu_{0} \lambda^{2} \mathrm{I} \phi_{\mathrm{xxxx}}-\mu_{\mathrm{TAN}} \mathrm{K} \phi_{\mathrm{xx}}+\rho \mathrm{I} \phi_{\mathrm{tt}}+\mathrm{H}(\mathrm{x}-\mathrm{a}) \sigma \phi=0
$$

where $v$ is Poisson's ratio and $\lambda / B \approx 0.3$ for the test piece. The second inclusion produces an effective stiffening of the beams ahead of the crack tip causing the loading wave to disperse in this region. One additional boundary condition stating that the axial stresses are zero must be applied at the load plane while at the far end of the sample two conditions, which state that both the axial and shear stresses are zero, are required. Equation (11) has been solved by employing an explicit finite difference scheme in which the values of the nonlinear coefficients are computed at the start of each timestep. These are then used to compute the rotations at the next timestep.

Reanalysing the experimental data using the nonlinear model produces the $G_{D}$ data shown in Fig. 7 for both the high and medium density grade materials. This Figure shows considerably less scatter in the range of $G_{D}$ values at any given crack speed than does Fig. 4 and it suggests that $G_{D}$ is almost independent of crack velocity. Additionally, the load variation for a typical test, computed by the nonlinear model, is now in much better agreement with the mean measured load. The average $G_{D}$ values for the high and medium density materials are 4.75 and $2.60 \mathrm{~kJ} / \mathrm{m}^{2}$ respectively. Obviously, on the basis of resistance to 
$\mathrm{RCP}$, the high density material is more suited to the pipeline application.

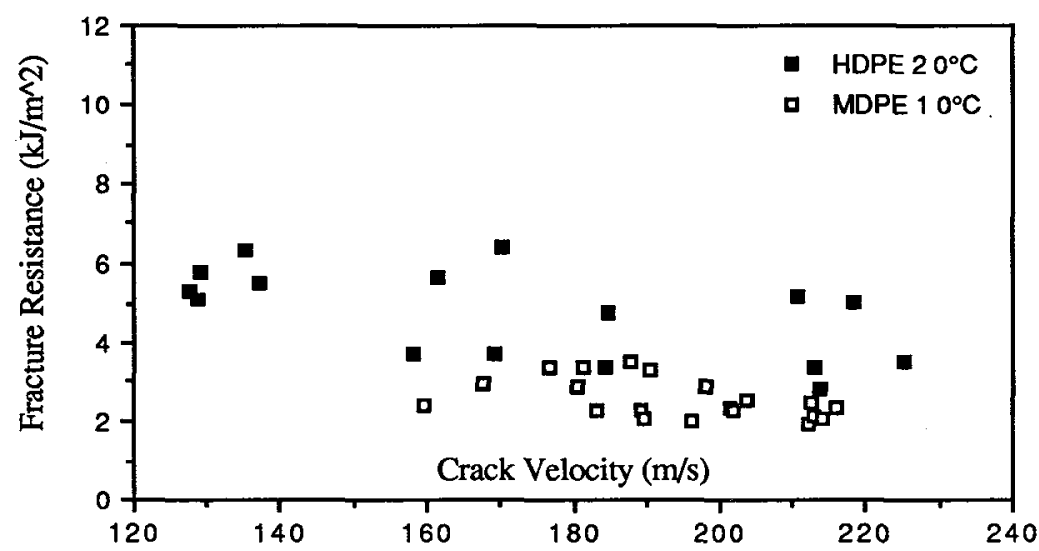

Fig.7 Variation in Fracture Resistance with Crack Velocity for Medium and High Density PE Grades (Nonlinear Analysis)

\section{REFERENCES}

[1] J.M. GREIG and L. EWING, Proc. of 'Plastic Pipes V', York, UK, (PRI, London), 8-10 Sept. 1982

[2] P.S. LEEVERS and J.G. WILLIAMS, J de Physique, 49, Supp. 9, C3, pp 231-236

[3] M.A. WHEEL and P.S. LEEVERS, Proc. 8th Euro. Conf. Fracture, Torino, Italy, (Engineering Materials Advisory Service, London, pp 867-872, Ed. D. Firrao), 1-5 Oct. 1990

[4] M.F. KANNINEN, Int. J. of Fracture, Vol.10 No.3, 1974

[5] W.F. AMES, Numerical Methods for Partial Differential Equations, (Nelson, 1969)

[6] R.W. TRUSS, R.A. DUCKETT and I.M. WARD, J. Mat. Sci. 19, pp 413-422, 1984

[7] J.M. GERE, J. App. Mech., Vol. 21, pp 381-387, Dec. 1954 